\title{
Analysis of the concept of informed consent concerning the use of genetic material according to the European Convention on Bioethics and in other solutionsm - Propositions for broad consent for future genetic research from the point of view of the activity of the Biobank
}

\author{
Rafał Patryn', Jarosław Sak ${ }^{1}$ \\ 1 Department of Ethics and Human Philosophy, Medical University, Lublin
}

Patryn R, Sak J. Analysis of the concept of informed consent concerning the use of genetic material according to the European Convention on Bioethics and in other solutionsm - Propositions for broad consent for future genetic research from the point of view of the activity of the Biobank. Ann Agric Environ Med. 2017; 24(3): 383-386. doi: 10.5604/12321966.1232088

\begin{abstract}
Objective. The aim of the article is a critical presentation of the typology of consents included in the European Convention on Bioethics and in other formal solutions concerning the gathering of genetic material in institutions called Biobanks. Materials and method. Existing types of Acts of Consent are inaccurate in their scope and possess insufficient information regarding the gathering of genetic material (application, usage, processing) and their final (future and diverse) use. Results. Lack of precise legal regulations on the broad future use of genetic material may result in various formal problems relating both to research participants as well as those commissioning the research. Ultimately, it may lead to various complications with the appropriate legal interpretation of consent and possible claims on behalf of the donors.

Conclusions. The presented proposition of consent with a terminal premise is to be applied eventually to legal and formal aspects of the collecting of genetic material. It is a possible solution which would clarify the issue of informed consent, and may be implemented in the regulations of the Convention as well as constitute a self-contained legislative solution to this matter. For example, Polish law in its current form, without the ratification of the Bioethical Convention, allows the collecting of material for genetic testing for determination of the risk of genetic defects in common genetic material from people who are planning to have a child.
\end{abstract}

Key words

The European Convention on Bioethics, law, informed consent, research

\section{INTRODUCTION}

Informed consent, which in the Convention concerns the terminal usage of genetic material, is not extensively detailed, and can be interpreted analogously and not directly. This may result from the fact that studies on solving the problem of storage of the collected genetic material in institutions called Biobanks are constantly being actively conducted in the search for satisfactory and rational solutions $[1,2,3]$. For example, Polish law in its current form, without the ratification of the Bioethical Convention, allows the collecting of material for genetic testing towards determination of the risk of genetic defects in common genetic material from people who are planning to have a child. The practical aim of the study, apart from the presented analysis, is to show that the adaptation of the Polish rule of perpetual usufruct with the maximal time of use set at 99 years, is a beneficial and rational solution to the problem of consent in biobanking. In this case, the widely-interpreted principle of the so-called analogiam iuris has been applied.

Address for correspondence: Rafał Patryn, Department of Ethics and Human Philosophy, Medical University, Lublin

E-mail:rpatryn@wp.pl

Received: 14 may 2013; accepted: 08 April 2014; first published: February 2017
Informed consent as the basic element in subjective permission of any action interfering in the bodily and psychical sphere of a person $[4,5]$. One of the definitions of 'informed consent' developed in the USA states that the patient has a right to an informed participation in all decisions including him/her in the treatment process, by providing clear, concise explanations of all aspects of the proposed medical treatment, with reasonable alternatives of medical conduct, assessment of risk of death, serious complications associated with each alternative method, determining the possible problems of recovery, and information on the possible outcome [6]. The patient has the right to know the details of diagnosis and to have access to medical records and test results at any time the patient so wishes. A competent patient cannot be subjected to any procedures or tests without a prior (informed) consent, and the physician obtaining the consent must be aware that it is inextricably linked with maintaining the patient's autonomy, understood as a subjective and free decision of will. Informed consent also includes providing relevant information, understanding the information, and assessment of consequences of the decision which may be foreseen by the physician $[7,8]$.

Biobanks as institutions for storing and using collected genetic material. Collecting genetic material with a 
subsequent possibility of using it is referred to as biobanking $[9,10]$. Biobanks are going through dynamic development worldwide, which was especially accelerated after the sequencing of the human genome in 2000, and are described thus:

(Biobanks) are either private or public institutions that collect biological material for clinical purposes (related to transplantation, transfusions, genetic diagnosis), for research purposes (e.g. research on neurodegenerative diseases, monovular twins or isolated populations), as well as for the purpose of police investigation $[2,3]$.

The Transplantation Act, amended in Poland in 2009, defines biobanks as: 'organizational units engaged in collecting, processing, sterilization, storage and distribution of human cells and tissues' [11]. Directive 2004/23/EC of the European Parliament and of the Council of 31 March 2004 on setting standards of quality and safety for the donation, procurement, testing, processing, preservation, storage and distribution of human tissues and cells, defines biobanks as 'tissue establishments', which means that they include tissue banks, hospital units or other units where activities connected with processing, preservation, storage and distribution of human tissues and cells are carried out. The facilities of this kind may also be responsible for procurement or testing of tissues and cells [12]. A key role in this type of institution is played by an appropriate legislative solution, including the solution to consent, storage and later (future) use of the collected genetic material.

Neither in Poland nor worldwide is there is any leading and instigating solution, and the existing standards specifying the type and the nature of consent are in the phase of proposed ideas rather than a formal model. Genetic population studies are characterized by a few specific traits which constitute their autonomy in comparison to many other scientific studies. They include: small risk to the donor, lack of knowledge of the tests' aim at the time of obtaining samples (data), and the studies' methodology (multistage, multilateralism, repeated use of the same sample) which frequently concerns rare genes and thus applies to a small number of participants $[13,14,15]$.

\section{The concept of consent in the European Bioethics} Convention and in other acts relating to the storage of genetic material. The most relevant from the formal point of view was the stance of the 1987 Madrid Declaration of the World Health Organization where, in subparagraph 3, we read: 'the method of inference in the human body has to be thoroughly discussed with the patient or his legal guardians and his consent must be conscious, voluntary and given in writing [16]. The Declaration clearly specifies the kind of consent, its conditions and form (information about which is missing in the European Convention on Bioethics [17]. According to subparagraph 12 of the Resolution from 17 April 1989 of the Parliamentary Assembly of the Council of Europe, during genetic research the patient's consent on providing information is necessary. This means that patient has the 'right to know, as well as the right not to know the results, and the physician has the duty not to inform others, including family members, without the patient's consent' [18]. Two Acts clearly define the importance of this basic condition, necessary for all interference in the human body. The requirement of undertaking by the physician or research team any treatments, tests, or other procedures on the patient is determined by the European Convention on Bioethics, which states that:

an intervention in the health field may only be carried out after the person concerned has given free and informed consent to it. This person shall beforehand be given appropriate information as to the purpose and nature of the intervention as well as on its consequences and risks. The person concerned may freely withdraw consent at any time [17].

Chapter V, subparagraph 16, point 5 of the Convention again mentions the required consent, which should be expressed in a clear manner, should pertain to specific studies and should be documented [17]. The article mentions a form of consent in a lapidary statement that it should be documented; thus, from the context it is possible to determine that the consent should be given in writing (or through electronic means by the so-called digital signature). Chapter VI, article 19, point 2 of the European Convention on Bioethics determines the requirements concerning consent for organ and cell procurement from living donors as follows: 'the necessary consent as provided for under Article 5 must have been given expressly and specifically either in written form or before an official body' [17]. This article specifies the conditions of the consent (to define precisely to what it should pertain), as well as its form (written). Unfortunately, in article 22, which is the key in matters concerning the activity of biobanks, neither the form nor the type of consent is provided:

when in the course of an intervention any part of a human body is removed, it may be stored and used for a purpose other than that for which it was removed, only if this is done in conformity with appropriate information and consent procedures [17].

The interpretation of this statement from the perspective of formal requirements (typology of acts of consent) of donating genetic material is the subject of the following part of the article.

Let us analyze the proposed and possible solutions to the issues of consent in other international Acts. The Bioethical Committee of UNESCO and the WHO propose a blanket consent for scientific research, which may be undertaken in the future [19]. This type of consent is, in its extension - a broad, signed Act characterized by a general nature and general content; it is a consent for almost anything, frequently without specification as to what the genetic material may be used for (without pointing out specific procedures characteristic for given research, etc.) [20].

The next element, which is extremely important, is the terminal nature of the consent, meaning the patient's will to consent with a time clause; a situation with which the patient either agrees or disagrees, and will or will not agree in the assumed future (e.g. in a specified future time). The proposed form of consent (in blanco - for almost anything) is a general and implied premise, very idealistic and incoherent which, in its scope, tries to foresee the current will of the concerned person about the future, however, without clear formal statements (e.g. 'I agree to future research on my genetic material', etc.). Another proposition is the so-called 'presumed consent with opt out', with a time clause after which the information on the genetic material should be withdrawn from the data base. The name indicates that this consent is similar to the general consent (in blanco), however, 
with a bigger unknown. Presumptions in this case can mean many things, including the presumption for what the genetic material could be used for (or for what it could not be used), and when the research is of great importance, this should be specified directly if possible at a given stage of the study. Although this type of consent would be most convenient for the researcher, its value and importance for future research, however, is questionable, partly because the donor should know what is happening to his genetic material.

On the other hand, the Council for International Organizations of Medical Sciences believes that if the tests are associated with minimal risks, and obtaining a consent might make the research impracticable, the Ethics Committee may waive the requirement of obtaining consent (or some of its elements) and make the decision as to the usage of the samples $[2,3,5]$. This statement gives rise to many doubts, beginning with its solution, which is ceding the donor's consent on various committees, and in turn, leads to a situation where basic human rights (freedom and liberty of will) are placed on the same scale as opinions of committees or other organizations. In its most paradoxical dimension this creates a situation where there is no consent from the donor himself (although not voiced) on using his genetic material, however, there might be a consent of 'some' assembly which may, in its interpretation, disrespect, disregard, and at the same time discriminate the freedom of will of the person and his right to decide for himself.

Another issue is the so called 'minimal risk' which would probably be overused by the commission that issues consents. Thus, the minimum risk criterion would have to be precisely determined and defined. In turn, T. Caufield proposes an authorization model which enables determination of which usage of samples the donor disagrees, to or in which situations he should be asked for additional consent (relevant clinical studies or commercial use of the results) $[2,3]$. This model is more empathetic for the research participants; however, a key matter would be its form - whether it would be in the form of a description within which things the participant agrees and disagrees, to would be included (this would complicate the Act), or perhaps this formula should be expressed through a specified questionnaire form with a list of terms and conditions under which the genetic material could be used (which would also prove to be difficult).

In turn, the First Genetic Trust, an American biotechnology company has developed a procedure of dynamic consent by mailing the donors information prior to using their samples. This approach also has its limitations, it may exclude samples from people who do not have access to these type of services (Internet) or lack the ability of using electronic mail (e.g. older people) $[2,20]$. Naturally, this is only one of the possibilities of complication, another is the form of relentless active participation of the donor in this process (imagine frequent questions, questionnaires and statements), which can put this method in an unfavourable light. Additionally, questions arise about the form that would prevail: would obtaining a general consent with additional subsections be adequate or should the subsections of the following Acts of Consent constitute a specific and separate formal part of an Act of Consent made somewhere in the past, and what would then be the relationship between these documents? Again, many doubts arise for an appropriate formal solution to this matter. The European Society of Human Genetics offered different rules for obtaining informed consent, depending on whether the collections existed earlier or whether they are being created. In the latter case, consent is always required; however, the existing biobanks can be divided into anonymous or identifiable collections. In the case of anonymous collections, the samples can be used without renewing consent (after acceptance of the Bioethics Commission), and in the second case, where consent would be required, this should be obtained by the researchers [21]. The solution is rational and consistent with legal regulations, although there is the question of whether the obtained and coded samples (without donor's data) at the moment of their acquisition come under the same law as those where the donor was identifiable, i.e. was this clearly specified and distinguished in the Act of Consent signed by the donor, or was it just signaled? Therefore, would there exist two separate forms of consent varying in subject or one with a specific form?

Another problem is again the requirement of assessment and evaluation of the Bioethics Committee and, in the case of the necessity to obtain additional consent, the problem of the donor's participation in the process (about which he could have already forgotten or does not want to be engaged in it any further). There also arises the situation in which a large group of donors demand a second approval to be obtained for any subsequent research. This situation, as described earlier, may be the source of many organizational and technological problems, such as the donor forgetting about the consent, does not want to remember for any reason, or does not have time nor the desire for this.

An important Act, Directive 2004/23/EC of the European Parliament and of the Council of 31 March 2004 on setting standards of quality and safety for the donation, procurement, testing, processing, preservation, storage and distribution of human tissues and cells, states in point 18 that as a matter of principle, tissue and cell application programmes should be founded on the philosophy of voluntary and unpaid donation, anonymity of both donor and recipient, altruism of the donor and solidarity between donor and recipient [12, 22]. This entry approaches the matter of storage of genetic material in a different way, namely the donation of cells and tissues should be anonymous and done on a voluntary basis, meaning, donation of the genetic material (e.g. tissues or cells) should be done without any formal determination (consent) of the act of giving and thus the conditions that follow (forms or written criteria). Underlining that this donation is anonymous, excludes the necessity to formalize the Acts of Consent including the existing and possible Acts of Consent.

The literature also presents a so-called honourable variant of genetic material donation. This is a form of quasi-donation with compensation for lost time and other inconvenience caused by the act of donation. The act of donation, however, does not cause the donor to lose the rights to decide about his genetic material (quasi), which may suggest that the prior consent can be withdrawn. In such a case, the question of a viable form of withdrawal of the consent and the time necessary for its execution arise. Would it be the time within the 'lifetime of the donor', or a future time determined by the donor in written form.

Propositions for a broad consent for future biobank research. Thus, a form of a written broad consent for future biobank research is postulated. The main aim of a written 
form of consent is for the donor to understand what he agrees to; thus, there must be an obligation to provide full information concerning the storage of the genetic material and the activities of biobanks. In the leaflet, or through verbal information (ideally both), the information on the scope (medical, commercial or other) and regulations (current) of the usage of the genetic material should be provided. There should also be information on what the material will not be used for and what legal rights the donor has for such as guarantee of security and insurance (this problem, however, should be a subject of a different article). The foreseen usage of the genetic material and its eventual purpose should then be determined in a formalized Act. The donor should be allowed to ask questions and acquire additional information. Another crucial issue is the broad determination of what the genetic material can be used for in the established and approximate future (expressed in years or decades) and the donors will as to those possibilities.

An essential issue worth underlining is the attempt at a formal determination of whether and who will have the rights to the collected genetic material in the future, that is, within the established time interval. This point should specify the length of the period of storage, which should be provided to the donor (or at least initially specified) by the researchers who could estimate (at least hypothetically) an adequate and rational time of storage of the genetic material and its usefulness for research.

The author sees a possible model solution stemming from a different legal regime and concerning a different field of regulations. The legislator introduced into civil law a concept of perpetual usufruct, which in Poland covers the period of 99 years. The premise, worthy of imitation in terms of time of genetic material storage, is ideal for stability between civil relations spread over time and possible legal guarantees through a period of few generations, and a time vector for defined plans and assumptions (placement, salary, etc.) concerning this regulation. The adoption of a specific time period concerning full rights to the collected genetic material (e.g. 50 years) with its specific formal character, would guarantee a subjective belief of the donors rights to his property, and would constitute a formal-legal stability regulating this field. Then, in a properly constructed Act of Consent concerning the storage and use of genetic material, there should be a disposition (or lack of it) of which the donor should be aware and agree or disagree as to whom and what rights will be given to the genetic material after the donor's death, the determination of the possibilities of inheritance of the genetic material or rights to it (in case of commercial exploitation). A final step should include a legible signature and attributing a Registration Number of the Act of Consent (in at least two copies). The above-mentioned and listed assumptions seem to be a priority and to be adequate to the discussed issue, of which a part of interpretation and circumstances will be found in the future, but which at present are impossible to determine or predict.

\section{REFERENCES}

1. Knoppers BM, Glass K. Human genetic research, DNA banking and consent: A question of „form”?, Clinical Genetics 59 (2001).

2. Pawlikowski J, Sak J, Marczewski K. Problemy etyczne i prawne związane z działalnością biobanków. Diametros. 2009; (19): 106-118.

3. Pawlikowski J, Sak J, Marczewski K. Biobank research and ethics: the problem of informed consent in Polish biobanks. Arch Med Sci. 2011; 7(5): 896-901.

4. Kauffman F, Cambon-Thomsen A. Tracing biological collections Between books and clinical trials. JAMA (299), 2008.

5. Bankowski Z, Levine RJ. Ethics and Research on Human Subjects. International Guidelines, www.cioms.ch/index.php/publications/ available-publications? task=view\&id $=14 \&$ catid $=53$

6. Etchells E, Gilbert BA. Bioethics for clinicians: 1. Consent Canad Med Assoc Jour. 1996

7. Ahronhein J, Moreno J. Ethics in clinical practice. Little, Brown and Co. 1994 Boston.

8. Annas GJ. A National Bill of Patients' Rights. Owned by the Massachusetts Medical Society. 1998; Vol. VI.

9. Stagmary B, Asplund K. Informed consent for genetic research on blood stored for more than a decade: A population based study. BMJ (325). 2002.

10. Armson BA. Umbilical cord blood banking: implications for perinatal care providers. Journal of Obstetrics and Gynaecology Canada. 27(3). 2005.

11. Transplantation Act [Dz. U. z 2015 r. poz. 793. 1893, 1991] http://www. poltransplant.org.pl/ust_jednoli.html

12. Directive 2004/23/EC of the European Parliament and of the Council of 31 March 2004 on setting standards of quality and safety for the donation, procurement, testing, processing, preservation, storage and distribution of human tissues and cells. http://eur-lex.europa.eu/ LexUriServ/LexUriServ.do?uri=OJ:L:2004:102:0048:0058

13. Williams G, Schroeder D. Human genetic banking: altruism, benefit and consent. New Genetics and Society. Volume 23, Issue 1, 2004.

14. Caulfield T, Upshur R, Daar A. DNA databanks and consent: A suggested policy option involving an authorization model. BMC Medical Ethics. (4:1)2003. http://www.biomedcentral.com/1472-6939/4/1

15. Hansson MG. Combining efficiency and concerns about integrity when us-ing human biobanks. Studies in History and Philosophy of Biological and Biomedical Sciences. (37) 2006.

16. Madrid Declaration of the World Health Organization [Deklaracja Madrycka Światowej Organizacji Zdrowia 1987] http://eur-lex.europa. eu/LexUriServ/LexUriServ.do?uri=OJ:L:2004:102:0048:0058

17. Convention for the protection of Human Rights and Dignity of the Human Being with regard to the Application of Biology and Medicine: Convention on Human Rights and Biomedicine http://conventions.coe. int/Treaty/en/Treaties/Html/164.htm (4.06.2013)

18. Resolution A2 - 327/88 on ethical and legal problems of genetic engineering, Official Journal C 96, 17/04/1989r., pg.1. http://www. codex.vr.se/texts/EP-genetic.html (dostęp: 8.06.2013)

19. Corrigan OP, Williams-Jones B. Pharmacogenetics: the bioethical problem of DNA investment banking. Studies in History and Philosophy of Biological and Biomedical Sciences. 37, 2006.

20. Flavio D'Abramo. Biobank research, informed consent and society. Towards a new alliance? J Epidemiol Community Health doi:10.1136/ jech-2014-205215.

21. European Society of Human Genetics. Data storage and DNA banking for biomedical research: technical, social and ethical issues. Recommendations of the European Society of Human Genetics. European Journal of Human Genetics.11(2003), Suppl.2.

22. Włoszczak-Szubzda A, Jarosz M. Professional Communications competences of nurses. Ann Agric Environ Med. 2012: 19(3). 